\title{
Geriatric Care in Nursing Curriculum in Saudi Arabia: A Nursing Student's Perspective
}

\author{
Laila Alharbi, BSN, $R N^{*}$ \\ Critical Care Nurse Specialist King Khaled Hospital, Hail, Saudi Arabia
}

\begin{abstract}
As the population continues to improve life expectancy rates, so too the numbers of elderly who require care outside the traditional family setting rises. This leads to an increased demand on the health care system and leads to more call for specialist geriatric and aged care nurses. However, there is an identifiable gap in nursing training in relation to geriatric and aged care in Saudi Arabia. Nursing students are limit provided clinical placement in nursing homes during their training and this has implications for retaining institutional learning and diffusion of power. This problem can be overcome with the addition within the curriculum of a clinical placement with nursing home setting.
\end{abstract}

Keywords

Aged care, Curriculum, Geriatric, Nursing, Student, Training

\section{Introduction}

Caring for the elderly and vulnerable has an important role in that nurses play in the well-being of society. The provision of care to the elderly and geriatric requires special knowledge and skills and is a discipline that is challenged to meet its work force requirements [1]. This specialised training may not always available, or provided inadequately, to nursing students at an undergraduate level $[2,3]$. While in the developed world, the nursing student could expect to have a practical placement and exposure within the geriatric setting [1], in Saudi Arabia this is not always the case. Little is known how effective not placements outside the hospital setting having has on the nurse's ability to meet the expected speciality competencies or level of type of clinical experience above physical assessment and communication skills [4].

There is often a great divergence in expectation of skill ability between the instructional setting and a clinical placement, and this deficit often involves more than the practical skills need. The nurses lack emotional intelligence that can only come with semi supervised clinical experience and social connection $[5,6]$. Furthermore, clinical placement allows for experimental learning, which leads to development of deeper knowledge, reduce initial anxiety in post-education work settings, and situational awareness [5,7], as well as impart institutional learning to the nurse.

This paper reflects, from a nursing student's perspective, on the content of the elderly and geriatric component of health care nursing curriculum in Saudi Arabia from the perspective of a nurse in training. I intend to examine the content of geriatric care in nursing education and relate it to the emerging need in the Saudi nursing education curricula. Significantly, at present there is no specific peer reviewed literature on geriatric training specific to Saudi Arabia.

\section{Geriatric Training in Undergraduate Educa- tion}

The last decades have seen an increase in global life expectancy, and consequently the number of ageing people increasing as a result [8]. This increase has resulted because of improved local health care services in many countries, in addition to the important role of the World Health organization in promoting better health services in less fortuned countries [9]. This increase in numbers of older adults $60+$ from $1.2 \%$ to $1.8 \%$ of the population over the last decade, has created a demand for skilful nurses who could provide quality and individualised care for the elderly $[10,11]$. But with evidence from literature of the limited presence of this training, it has become very important that nurses have geriatric literacy to provide care for the elderly $[3,8]$.

Internationally, geriatric training at the undergraduate level fundamentally involves understanding an abridged Orem's

*Corresponding author: Laila Alharbi, Critical Care Nurse Specialist King Khaled Hospital, Hail, Saudi Arabia

Accepted: June 27, 2020

Published online: June 29, 2020

Citation: Alharbi L (2020) Geriatric Care in Nursing Curriculum in Saudi Arabia: A Nursing Student's Perspective. J Nurs Pract 3(1):139-142

Copyright: (C) 2020 Alharbi L. This is an open-access article distributed under the terms of the Creative Commons Attribution License, which permits unrestricted use, distribution, and reproduction in any medium, provided the original author and source are credited. 
self-care deficit nursing theory to enable assistance with daily needs conducted over one semester [3]. Added to this may be some general information on practice from general first year studies, and if selected, a third-year elective [3]. Students, therefore, in Saudi Arabia, can expect to gain between 8-12 weeks training in all aspects of geriatric care including placement training, which is delivered by academics and ward supervising nursing staff. In general, nursing program have students periodically immersed within a home clinical setting for training [12]; however, in Saudi Arabia this expose to real practice is lacking in most general nursing courses. At this level of exposure, is problematic for the student to gain insights into practice conditions without that expose; this lack of expose in the field limits the health literacy for the nurse.

Geriatric health literacy indicates the knowledge and skills needed by nurses to provide holistic care to senior patients or clients [13]. This care considers the special needs of this age group, their characteristics, such age, medical condition, gender, educational and academic background, and their personal requirements, including their religious and cultural [14]. Geriatric care should also consider the current condition of the elderly, including health condition, mental and cognitive abilities, social requirements and spiritual needs. Although general nursing education provides some training opportunities to nursing students on special topic about caring for elderly, there is still an obvious need for more, and this can only be achieved in Saudi Arabia with addition in house nursing training within aged care facilities [15].

\section{The Impact of Specialised Education on Im- proving Geriatric Care}

There is a considerable amount of data about the general gerontology; however, the effect of undergraduate educational preparation to provide direct care for the elderly is not clearly presented [16], including providing an abuse-free care. Abuse here refers to nurses' lack of ability to assess, plan, implement and evaluate adequate quality care to the elderly [17].

The development and application of models within nursing programs that deal with elderly as a minority may decrease incidence of unintentional abuse that occur due to lack of knowledge and skills about this age group $[18,19]$. Although the actual prevalence of elder abuse in many countries, including the USA and Australia, is not clearly identified, most reported cases of abuse take place at home [20]. The abusers are usually family members, most likely the victim's spouse or an adult child who serves as a care-giver [21]. One reason for the level of perved abuse was explored by Lin, et al. [22] who noted that while there was training in geriatric care in Taiwan, there was little in the way of preparing students for working with high end care needing clients, such as those with advanced dementia. A multidisciplinary approach and the provision of educational material to family members can be beneficial in modifying the professionals' as well as spouses' attitudes and practice [23]. So, nursing students can be trained on formulating teams and managing this role as educators (like in the case of the Saudi groups mentioned above).
The issue of inadequate education about geriatric care is also a concern among other health care professionals, including physicians and physiotherapists $[4,23]$. As nurses are the key health care provider in geriatric care, they can be team leaders who coordinate health services to the elderly. Thus, the promotion of partnership among health professionals can improve significantly geriatric care.

Although adequate training in clinical setting can modify practices, nurses must also have educational component provided in the theoretical courses so that they can build their attitudes based on a wider scope of understanding of the special needs and requirement this age group often requires [24]. The Saudi nursing programs have not been structured to prepare nurses to care for the elderly. Even the currently provided material is still based on limited didactic and clinical experience, which is often caring for the elderly in hospital setting. Once geriatric care theoretical material has been modified, there is a need for more emphasis on applying theory to practice in areas where elderly are present, including community and nursing homes [25]. Nurses are primarily the health care professionals who provide direct care to the elderly; nurses are the gatekeeper toward the elderly in hospitals and nursing home [2].

\section{Undergraduate versus Continuing Education and Training}

The need to include geriatric care training in the formal education has been the issue of concern for many researchers $[8,14,22]$. There are also many reports on the need for training of nurse already working in nursing homes and community centres and provide care to the elderly [26]. This can be best achieved through a well-structured, rewarding career path for nurses trained to be gerontological nurse specialists and care assistants [9].

When examining nursing students' attitudes toward caring for the elderly and the impact of curriculum changes, many studies reported positive knowledge, skill and attitudes [10]. It is, therefore, very beneficial integrate this knowledge and training within the formal education and then continue this emphasis after graduation through providing a specialized continuous education while working [2,27].

The importance of education about the elderly extends to the clinical settings. While there is limited research into training and aged care globally, researchers reported that continuing education in the clinical settings that involved aged care had improved practice, attitudes and care outcome $[10,28]$. A study by Shah, et al. [28] evaluated the effect of the Geriatrics Education for Emergency Medical Services training program on emergency medical service providers in a rural community in New York. A total of 88 emergency care providers in Livingston County participated in the 1.5-day continuing education program that covered topics like changes with age, communicating with older adults and their caregivers, elder abuse and neglect, end-of-life care issues, assessment, falls, and altered mental status. The participants completed the Geriatric Attitude Scale, a class satisfaction survey, and a survey evaluating comfort in caring for older adults [29]. The median comfort 
scores were significantly increased for the domains of communications, medical care, abuse evaluation, and falls evaluation [28]. This study signifies the importance of education, undergraduate and in the clinical settings, in modifying the knowledge, practices and attitude of health professionals towards the elderly. Both undergraduate formal education and on-job continuous training can improve nurses' knowledge and attitudes toward the provision of quality geriatric care.

\section{Building Partnerships between Academics and Clinicians: A Student's Perspective}

In Saudi Arabia, a committee has been formed recently by ministerial mandate responsible for formulating a strategic plan to promote community-based health care for the elderly. The aim was to provide care to elderly patients in the home setting, and was expected that a consequence hospital admissions for the elderly will decrease. These community groups, which are composed of physicians, nurses and health educators, should be trained to meet the required needs of those senior citizens. However, the content of geriatric care during my undergraduate training was very limited; it was based on a module in one or two courses. The training also was focused on caring for only hospitalised elderly. I believe that this content is inadequate and requires an increase and an expansion of its scope in the undergraduate Saudi nursing programs.

Learning process for nurses is an everlasting experience necessary to provide quality, including geriatric care [18]. In order to achieve the objective of quality teaching about geriatric care, it is essential to build a partnership between educators of the university and geriatric clinical specialists [9]. Successful partnerships need to involve effort, time and commitment to develop prompt blueprints and plans of action. Academic- clinician didactic partnership requires many planning meetings to allow participants to identify needs and requirements for each party, share ideas, build relationships, discuss plans, and other resources. In order to ensure this partnership, each partner needs to derive benefit and weigh risks and returns involved with this partnership [16].

Positive outcomes that may result from such partnerships include the enhanced relationship between the clinicians at one end and the academic partner; increased the provision of potential registered nurse applicants to that health care facility, whether it was a hospital or a nursing home; increased availability of master's-prepared clinical faculty for use by the academic partner to bridge the faculty gap; increased availability of clinical sites for the education partner, which is an issue in many nursing faculties; improved collaboration for research; and increased presence of service partner in the academic environment [30]. The purpose of the partnership can also expand the educational scope of nursing program by introducing preceptor ship and mentorship models to their clinical courses [16]. This can be done by allowing hospital-based nurses, who have a well-established geriatric care training, to teach part of the clinical component of nursing courses. Hence, students may experience an improved attitudes as well as skills in geriatric care [10].

\section{Summary}

There is a need to include an additional clinical placement component on geriatric care in undergraduate nursing curriculum. Although improvements in geriatric care have been achieved, there is still room for improvements in the training and in the preparedness of nurses entering geriatric care. The current components in Saudi Arabian nursing curricula is demonstrably inadequate in both providing training outside the lecture and ward setting, and in the preparedness of nurses to enter practice. It would be appropriate for more clinical setting training for nurses to be given, particularly clinical placement in age care facilities which is lacking in the current training programme. In addition, within the practice setting, clinical experts who provide care to the elderly can benefit nursing students by mentoring or precenting them or by acting as role models. Given the aging population, and the increased reliance on out of home intuitional care, the nursing curriculum must reflect the growing demands on nursing practice of age care.

\section{References}

1. Hawkley L, Long M, Kostas T, et al. (2018) Geriatrics training for nurses in a skilled nursing facility: A GWEP feasibility study. Geriatric Nursing 39: 318-322.

2. Donahue M, Kazer MW, Smith L, et al. (2011) Effect of a geriatric nurse education program on the knowledge, attitudes, and certification of hospital nurses. Contin Educ Nurs 42: 360-364.

3. Imai Y, Onishi C, Bando T (2017) Students' care-related attitudes during geriatric nursing training. International Journal for Human Caring 21: 176-184.

4. Mezey M, Stierle $\sqcup$, Huba GJ, et al. (2007) Ensuring competence of specialty nurses in care of older adults. Geriatric Nursing 28: 9-14.

5. Perlman D, Taylor E, Moxham L, et al. (2018) Examination of a therapeutic-recreation based clinical placement for undergraduate nursing students: A self-determined perspective. Nurse Educ Pract 29: 15-20.

6. Hurley J, Huctinson M, Kozlowski D, et al. (2019) Emotional intelligence as a mechanism to build resilience and non-technical skills in undergraduate nurses undertaking clinical placement. Int J Ment Health Nurs 29: 47-55.

7. Perlman D, Taylor E, Moxham L, et al. (2017) Innovative mental health clinical placement: Developing nurses' relationship skills. J Psychosoc Nurs Ment Health Serv 55: 36-43.

8. Potter G, Clarke T, Hackett S, et al. (2013) Nursing students and geriatric care: The influence of specific knowledge on evolving values, attitudes, and actions. Nurse Education in Practice 13: 449-453.

9. Sullivan-Marx EM (2013) Is it time for a public health nursing approach to aging? J Gerontol Nurs 39: 13-16.

10. Shin J, Xiao LD (2012) Factors affecting nursing students' intention to work with older people in China. Nurse Education Today 32: 219-223.

11. Asharaf AS (2013) Aging in Saudi Arabia: Impact on demographic transition. BOLD 24: 13-26.

12. Midgley K (2006) Pre-registration student nurses perception of the hospital-learning environment during clinical placements. Nurse Educ Today 26: 338-345. 
13. Cutilli CC (2007) Health literacy in geriatric patients: An integrative review of the literature. Orthop Nurs 26: 43-48.

14. Haron Y, Levy S, Albagli M, et al. (2013) Why do nursing students not want to work in geriatric care? A national questionnaire survey. International Journal of Nursing Studies 50: 1558-1565.

15. McConnell ES, Lekan D, Bunn M, et al. (2009) Teaching evidence-based nursing practice in geriatric care settings. The geriatric nursing innovations through education institute. J Gerontol Nurs 35: 27-33.

16. Abendroth $M$, Graven $\amalg$ (2013) Integrating care of older adults into the nursing curriculum: A case exemplar project. J Nurs Educ 52: 529-532.

17. Holroyd A, Dale S, Fehr C, et al. (2009) Attitudes toward aging: Implications for a caring profession. J Nurs Educ 48: 374-380.

18. Wendel VI, Durso SC, Cayes D, et al. (2010) Implementing staff nurse geriatric education in the acute hospital setting. Medsurg Nurs 19: 274-280.

19. Ballard C, Corbett A, Orrell M, et al. (2018) Impact of person-centred care training and person-centred activities on quality of life, agitation, and antipsychotic use in people with dementia living in nursing homes: A cluster randomised controlled trial. PLoS Medicine 15: e1002500.

20. Roberto KA, Teaster PB, Duke JO (2004) Older women who experience mistreatment: Circumstances and outcomes. Journal of Women \& Aging 16: 3-16.

21. The National Center on Elder Abuse (2007) An elderly abuse report.

22. Lin PC, Hsieh MH, Chen MC, et al. (2018) Knowledge gap regarding dementia care among nurses in Taiwanese acute care hospitals: A cross-sectional study. Geriatr Gerontol Int 18: 276-285.
23. Goldenhar LM, Margolin EG, Warshaw G (2008) Effect of extracurricular geriatric medicine training: A model based on student reflections on healthcare delivery to elderly people. J Am Geriatr Soc 56: 548-552.

24. Mezey M, Mitty E, Buger SG (2008) Nursing homes as a clinical site for training geriatric health care professionals. American Medical Directors Association 10: 196-203.

25. Scott-Tilley D, Marshall-Gray P, Valadez A, et al. (2005) Integrating long-term care concepts into baccalaureate nursing education: The road to quality geriatric health care. J Nurs Educ 44: 286-290.

26. Eyers I, Bryan K (2006) Professionalising the care of older people: Transforming the workforce. Quality in Ageing and Older Adults 7: 37.

27. Ferrario CG, Freeman FJ, Nellett G, et al. (2007) Changing nursing students' attitudes about aging: An argument for the successful aging paradigm. Educational Gerontology 34: 51-66.

28. Shah MN, Rajasekaran K, Sheahan WD, et al. (2008) Effect of the geriatrics education for emergency medical services training program in a rural community. Journal of the American Geriatrics Society 56: 1134-1139.

29. Levine SA, Chao SH, Brett B, et al. (2008) Chief resident immersion training in the care of older adults: An innovative inter-specialty education and leadership intervention. J Am Geriatr Soc 56: 1140-1145.

30. Murray TA (2008) An academic service partnership to expand capacity: What did we learn? The Journal of Continuing Education in Nursing 39: 217-224.

DOI: $10.36959 / 545 / 374$

Copyright: (C) 2020 Alharbi L. This is an open-access article distributed under the terms of the Creative Commons Attribution License, which permits unrestricted use, distribution, and reproduction in any medium, provided the original author and source are credited. 